\title{
Reply to the letter from Damman et al.: Heart transplantation in the Netherlands: a national achievement
}

\section{Y. Pinto ${ }^{1}$}

Published online: 8 March 2018

(c) The Author(s) 2018. This article is an open access publication.

We appreciate the response provided by colleagues Damman, Brügemann, De Boer, Erasmus and Van den Broek to the overview of heart transplantation at the UMCU [1] and accompanying editorial [2]. It is well taken that indeed the transplant programme at the UMCG in Groningen has developed into a strong and essential part of the total heart transplant programme in the Netherlands, and should be recognised as such. In that respect I would like to highlight that the authors nicely show that we are in the fortunate position that heart transplantation is indeed a national endeavour with equally important contributions from the three centres in Rotterdam, Utrecht and Groningen.
Open Access This article is distributed under the terms of the Creative Commons Attribution 4.0 International License (http:// creativecommons.org/licenses/by/4.0/), which permits unrestricted use, distribution, and reproduction in any medium, provided you give appropriate credit to the original author(s) and the source, provide a link to the Creative Commons license, and indicate if changes were made.

\section{References}

1. Sammani A, Wind AM, Kirkels JH, et al. Thirty years of heart transplantation at the university medical centre Utrecht. Neth Heart J. 2017;25:516-23.

2. Pinto YM. Three decades of heart transplantation in the Netherlands. Neth Heart J. 2017;25:469-70.
Y. Pinto

y.pinto@amc.uva.nl

1 Department of Cardiology, Academic Medical Center,

University of Amsterdam, Amsterdam, The Netherlands 